\title{
DETERMINATION OF BEARING QUALITY USING FREQUENCY VIBRATION ANALYSIS
}

\author{
ŽIARAN Stanislav ${ }^{1 *}$, CHLEBO Ondrej ${ }^{1}$, ŠOOŠ L'ubomír ${ }^{1}$

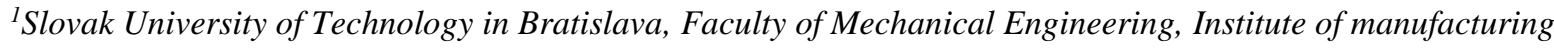 \\ systems, environmental technology and quality management, Nám. Slobody 17,812 31 Bratislava, Slovakia, \\ $e$-mail: stanislav.ziaran@stuba.sk
}

\begin{abstract}
The paper proposes two methods for determining the quality of industrially manufactured bearings, where the vibro-acoustic energy is expressed by measuring the vibration acceleration. The determined criteria were verified and $100 \%$ agreement was reached in determining the required quality of the bearings. Unwanted bearing noise emissions and its faults can be monitored over the maximum acceleration value determined from the time history, the frequency distribution and the r.m.s. value of the determined frequency range.
\end{abstract}

KEYWORDS: bearing; quality; frequency analysis; vibration; noise.

\section{Introduction}

Previous vibro-acoustic analyses clearly confirm that bearings significantly affect the dynamic behavior of rotating components of machinery and mechanical systems, not only in terms of noise and vibration (dynamic load), but also in terms of the reliability and lifetime of the machine and/or mechanical system [4, 7]. Unwanted bearing clearances and/or fault of the bearing increase the amplitude of the imbalance of the rotating components at the rotational frequency and thus the undesired low-frequency noise and vibration. Low-frequency vibration disrupts the surrounding building structures; in the living environment it causes vibration of various components of building structures and loose objects, and thus affects the human environment and reduces the reliability and lifetime of mechanical systems [2, 7, 12]. Lowfrequency vibration generates low-frequency noise, which in an enclosed space can, at a certain position of the noise source, cause standing waves, manifested as a rumbling noise annoying humans [7]. Therefore, it is desirable to monitor the quality of bearing production and installation using an objective methodology [8].

Vibro-acoustic waves generated during quality tests or operation of machinery components contain a lot of useful information about their technical condition and also reflect the nature of work processes and the intensity of the load of the component or the machine itself. Unlike other diagnostic methods, vibro-acoustic diagnostics makes it possible to determine not only a structural defect or faults, but also their causes (e.g. ovality, excessive internal clearance, defective bearing components, inappropriate and unprofessional assembly and/or installation).

Reducing the dynamic load of machines, mechanical systems and their parts with respect to the environment and humans is reflected in reduced emissions and immissions of noise and mechanical vibration, thus improving the work environment and the surrounding area $[1,2]$. The article deals with vibro-acoustic analysis of the quality of new bearings applied in mechanical systems, such as water pumps and washing machines, and complements an already published article [8]. It is precisely in mechanical systems working in proximity to humans that 
high-quality bearings that generate the lowest possible noise level are most necessary. The reduction of vibrations and noise must focus first and foremost on the primary reduction of their noise levels, i.e. directly on the elimination of the causes of unwanted vibro-acoustic energy of technical equipment, and this area primarily includes bearings $[5,6,10]$.

\section{The aim, methodology of vibro-acoustic measurements and measuring technique}

The aim of experimental tests performed on the test equipment (new bearings for water pumps) and directly on the product (electric motor and washing machine drum) was to a) identify the causes of excessive dynamic load (vibration and noise) and b) determine the procedures for evaluating bearing quality, especially in terms of noise, and c) verify their objectivity both in terms of repeatability and reproducibility of measurements in determining the permissible noise limits for bearings used in selected mechanical systems. The procedure for determining the quality criteria of bearings mentioned in this article can be generalized for different types of bearings respecting the representative statistical selection of the examined type of bearing.

The procedure for evaluating the quality of bearings in terms of their noise is based on the dynamic behavior of the bearings, i.e. on the evaluation of the parameters of mechanical vibration quantities. The aim of measuring the acceleration and magnitude of the periodic dynamic load (vibration) was to analyze the size of the kinematic quantities (acceleration and velocity) acting on the bearing flange, or on its installation in the mechanical system. The vibration quantities are not affected by the ambient vibration as in the case of sensing an audio signal which is more or less affected by residual noise (background noise) [5, 9]. The selected methodologies are therefore based on a logical relationship between mechanical and acoustic vibration. A frequency analysis whose aim was to determine the frequency distribution of a significant undesirable dynamic load and its causes was performed. As the methodology for assessing the quality of manufactured and already installed bearings of rotating components of the mechanical system must clearly and reliably evaluate satisfactory and unsatisfactory bearings with repeatability and/or reproducibility, the selected methodology was based on the relationship between mechanical and acoustic vibration.

When measuring mechanical and acoustic vibration, the most modern measuring technology from the company Bruel \& Kjaer $(\mathrm{B} \& \mathrm{~K})$ was used, namely the 12-channel measuring card B\&K PULSE; accelerometers with usable frequency ranges from $0.2 \mathrm{~Hz}$ to $12800 \mathrm{~Hz}$; integrating the accelerometer measuring vibrometer with the output of the vibration severity, which is a quantitative and qualitative indicator of the dynamics of machinery with rotating and reciprocating masses, as well as impact loads in accordance with STN ISO 10816 and STN ISO 2954 standards; a sound analyzer with a usable frequency range up to $25600 \mathrm{~Hz}$ for the control recording of measured signals, including residual noise, which represents an open system providing new possibilities and more information and reliability in the process of measurement, analysis, evaluation and expertise; B\&K impact hammer with a maximum impact force of $35584 \mathrm{~N}$ to excite the structure's own vibration shapes when verifying the measuring network, and other additional techniques supporting the measurement.

\section{Dynamic bearing load}

Machines and machinery, and thus also bearings operate at a constant and/or variable dynamic load, which has an effect on the behavior of generating the levels of vibration and noise quantities. For the test equipment of a given type of bearing, the load of the new bearing and its rotational frequency were constant. With the new bearings installed in the electric motor of the washing machine, the load and their rotational frequency were variable. 


\subsection{Constant dynamic bearing load}

Figure 1 represents a selection from a sufficiently representative statistical sample (30 bearings) of the time history of the measured vibration accelerations from the dynamic load generated by a satisfactory (top) and unsatisfactory (bottom) bearing of the type examined. The amplitude of time history of vibration acceleration is approximately constant with low amplitude in satisfactory bearings, in contrast to unsatisfactory bearings, where the amplitude of vibration acceleration is on average several times greater with more pronounced regular, and irregular maximum amplitudes reaching high values of vibration acceleration characteristic of pulse jerking. These deterministic or random maximum signal amplitudes are a manifestation of fault to the bearing races of the bearing, or its components, caused by the production and/or technology of the bearing installation. A more detailed specification is possible using frequency analysis, which allows to detect the causes and types of bearing fault. Abnormal temporal dynamic manifestation of the bearing through the maximum allowed value of vibration acceleration is one of the criteria for objective evaluation of bearing quality [8]. The maximum allowed value is determined by the bearing type. A more detailed specification is possible using frequency analysis, which allows to detect the causes and types of bearing faults and to detect the type of production operation where the fault occurs based on the type of the fault in production. However, this is not the purpose of the present article.
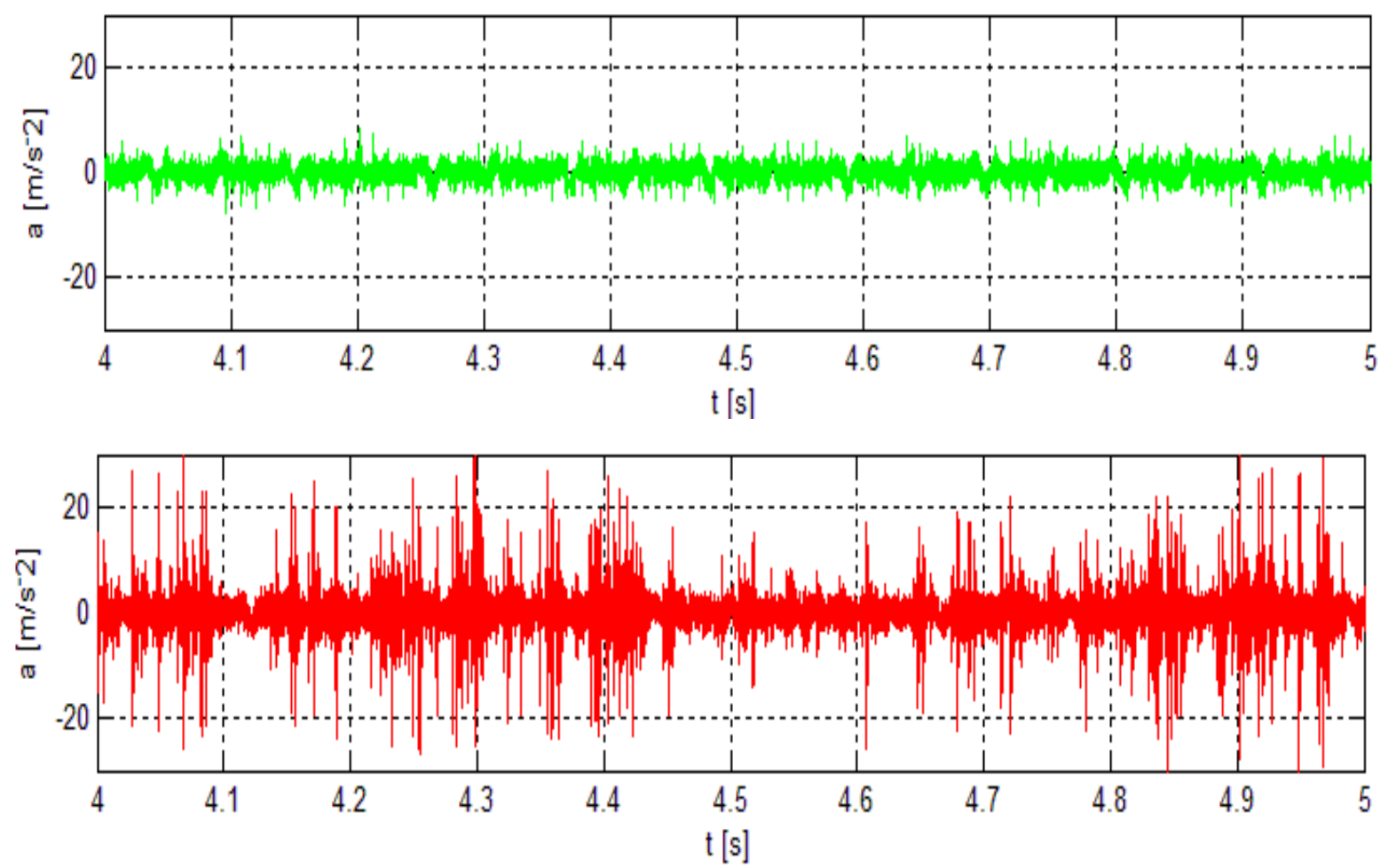

Fig. 1 Time history of dynamic bearing load; top- satisfactory, and bottom- unsatisfactory

\subsection{Variable dynamic load}

In the case of quality assessment of already installed bearings, the dynamic load changes due to an increase, or decrease in the rotational frequency, which is typical for washing machines, when the rotational frequency approximately doubles is changed. Frequency spectra (thirdoctave band and FFT analysis) at braking and rotational frequency (5 810 - 6330$) \mathrm{r} / \mathrm{min}$ (according to photoelectric tachometer probe MM 0024) and according to the monitoring of the maximum deviation of the rotational frequency in the spectrum FFT $8100 \mathrm{r} / \mathrm{min}(135 \mathrm{~Hz})$ are shown in Figure 2. At a mean frequency of $500 \mathrm{~Hz}$, the noise level was exceeded due to greater bearing clearance [11]. 


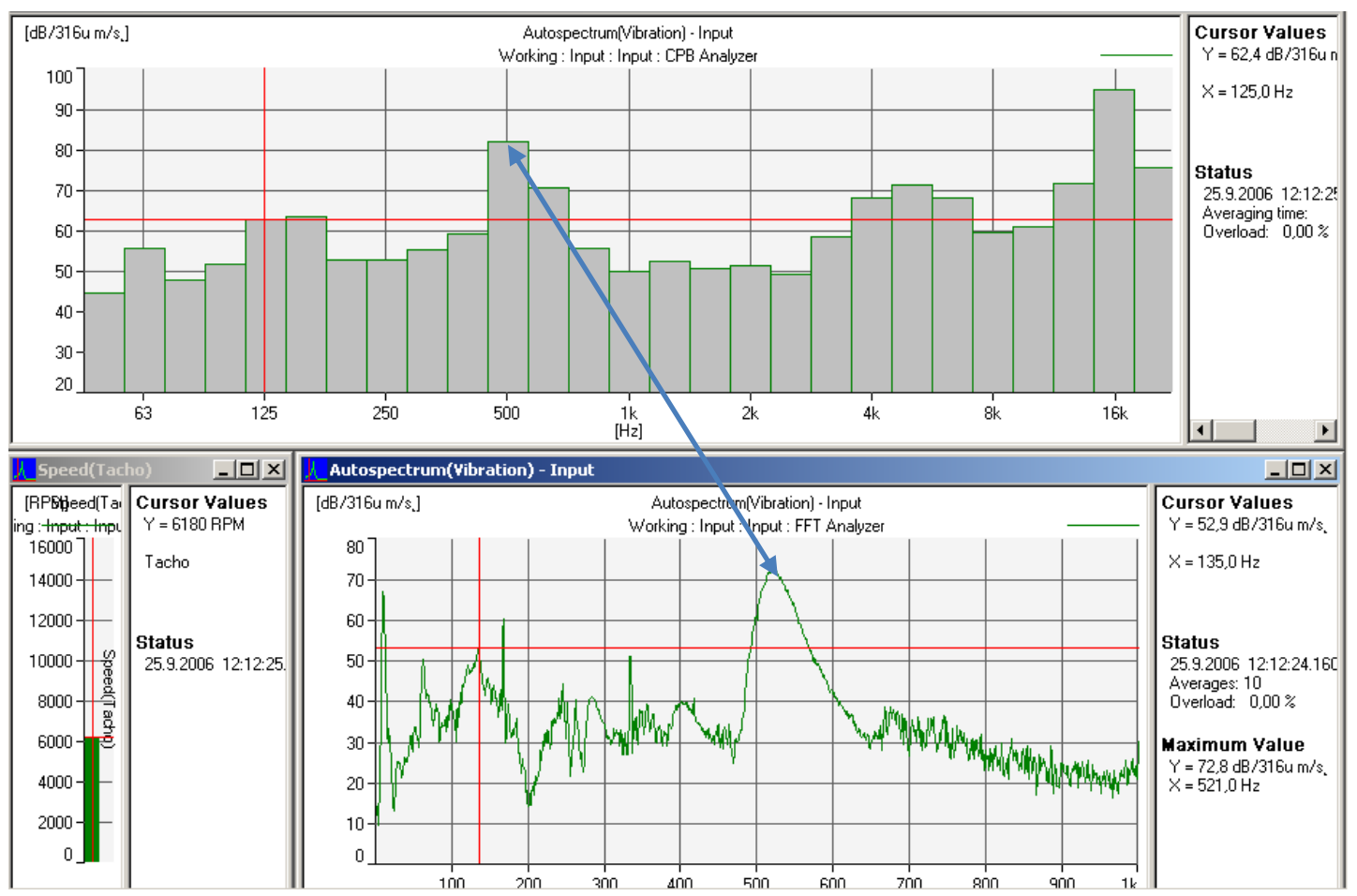

Fig. 2 Frequency spectra during braking related to the change in rotational frequency

\section{$4 \quad$ Procedure for determining the quality of bearings}

\subsection{Frequency analysis of the bearing itself}

From the above time history (Fig. 1), a frequency analysis of a representative statistical sample of bearings was performed in order to determine the frequency interval suitable for determining the quality criteria of bearings (Fig. 3). From the frequency distribution of the vibration acceleration, expressed in decibels, significant amplitudes can be seen in the frequency range from $1.5 \mathrm{kHz}$ to $4.5 \mathrm{kHz}$, where the human auditory organ is most sensitive. It should be emphasized that this interval will vary for each bearing type. This frequency interval with an equivalent level of vibration acceleration in this interval for a suitable bearing in conjunction with the time history of the vibration acceleration are verified criteria for the bearing quality limit of the given type [8].

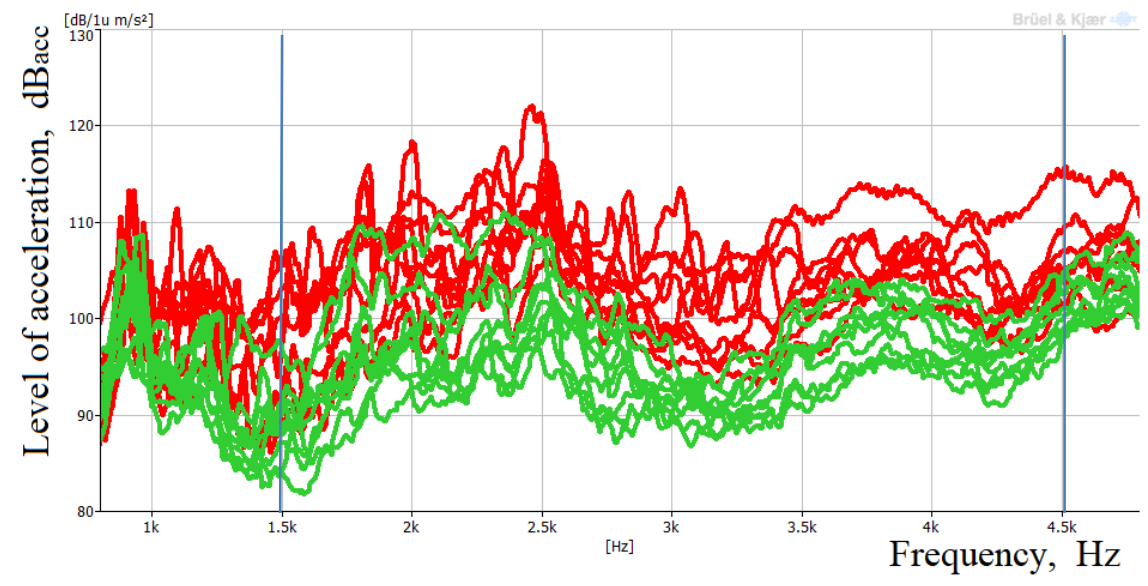

Fig. 3 Frequency spectra of bearings with different dynamic emission; spectra shown in red (b\&w - darker) represent unsatisfactory bearings and in green (b\&w - paler) represent satisfactory bearings 


\subsection{Frequency analysis of washing machine electric motor bearings}

Low-frequency sound (noise) exposing living spaces is also generated by household appliances and sanitary equipment of the dwelling. However, the noise level values themselves are not always critical. Participation in the negative effect of a noise source or activity, as a source of noise in the near surroundings, has in particular the frequency distribution of noise (sound), the presence of tonal components, variability, impulsivity and noise interruption. Most household appliances and sanitary ware emit medium and higher frequency acoustic waves when used. A typical example of an exception is an automatic washing machine in the spin mode, when a very pronounced low-frequency tonal wave is generated, which causes unpleasant pressure on the eardrum, even though the wave is usually located in an enclosed space. The frequency spectrum of the washing machine when spinning the laundry obtained by measuring over two mutually perpendicular sound-reflecting planes (floor, wall) into the free space is shown in Figure 4.

The electric motor of the washing machine, including the drum, excites periodic vibration of relatively high intensity in the range of working rotational frequency, due to the imbalance of rotating components, the vibration amplitude of which also depends on the quality of the bearings (especially on the clearance in the bearing). The magnitude of the amplitude of the vibration quantities at the rotational frequency depends on the accuracy of the balance and the quality of the bearings. An increased clearance in the bearings increases particularly the moment imbalance.

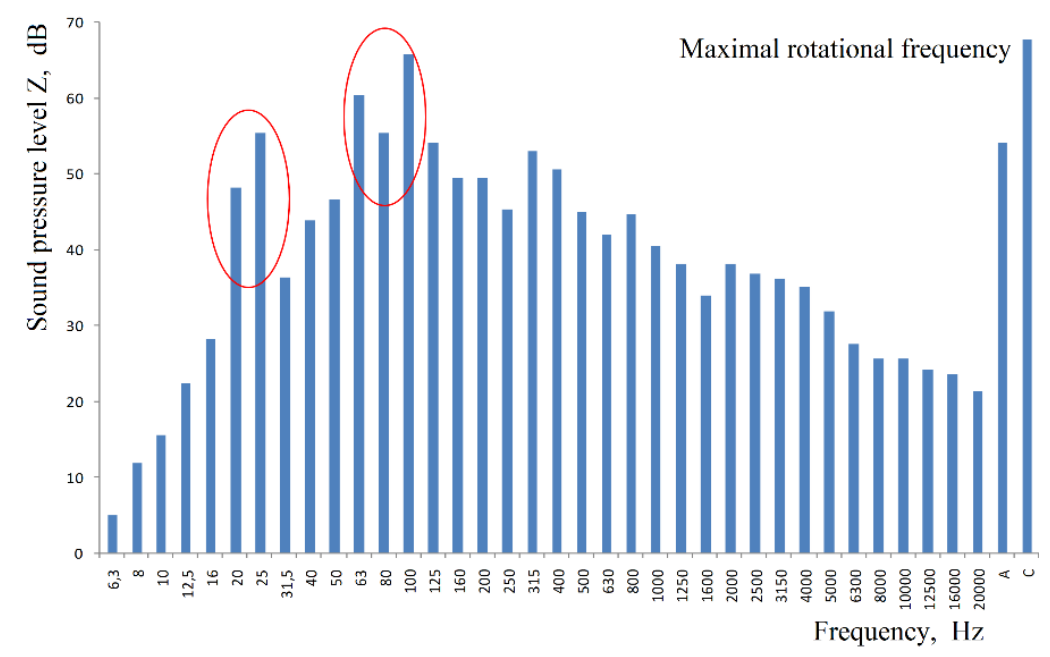

Fig. 4 Unweighted one-third-octave spectrum of the washing machine during spinning

Based on previous experience, the amplitude of the vibration quantities from the imbalance is relatively large and can be one of the causes of excitation of the resonant phenomena of the electric motor. The degree of balance is usually determined by the manufacturer, which may not always correspond to the required dynamic load of the electric motor and the surrounding structures. The amplitude of the vibration from the imbalance increased with the increasing rotational frequency and reached a frequency of up to $117 \mathrm{~dB}_{\text {acc }}$ at a frequency of $250 \mathrm{~Hz}$ [11]. The amplitude from imbalance in the diagnosed engines was approximately the same at the corresponding rotational frequency. In most cases, it did not exceed $1 \mathrm{~dB}$. This may indicate a higher quality of balance and the use of higher quality bearings.

Based on the frequency analysis performed at different frequencies in the operating interval, it was found that the increased dynamic load occurs at a frequency around $135 \mathrm{~Hz}$, which corresponds to an operating rotational frequency of $8100 \mathrm{r} / \mathrm{min}$ (Fig. 5). In the frequency spectrum, this is manifested by a significant amplitude of the vibration of the fourth harmonic 
(4H) around the frequency of $540 \mathrm{~Hz}$, which was also confirmed by previous measurements [11]. From the frequency spectra it can be stated that the amplitude of the vibration quantities at the frequency (approximately $540 \mathrm{~Hz}$ ) gradually decreases with the decreasing and increasing rotational frequency, which is characteristic of the resonant phenomenon, or critical rotational frequency of the electric motor shaft, their multiples - harmonic or fractional multiples - subharmonic.

If the harmonics or sub-harmonics of the critical shaft's rotational frequency coincide with the excitation frequency or its harmonic frequencies, the resonant state of the rotor of the electric motor and/or the drum occurs, which can manifest itself in excessive dynamic loads despite certain design and technological deficiencies (errors), such as the rotor itself is very rigid (natural frequency $683 \mathrm{~Hz}$ [11]). In this case, design and technological errors must be understood primarily as an increased imbalance, greater clearances or poor quality (unsatisfactory) bearings. However, the problem might also be an inaccurate and inconsistent installating.
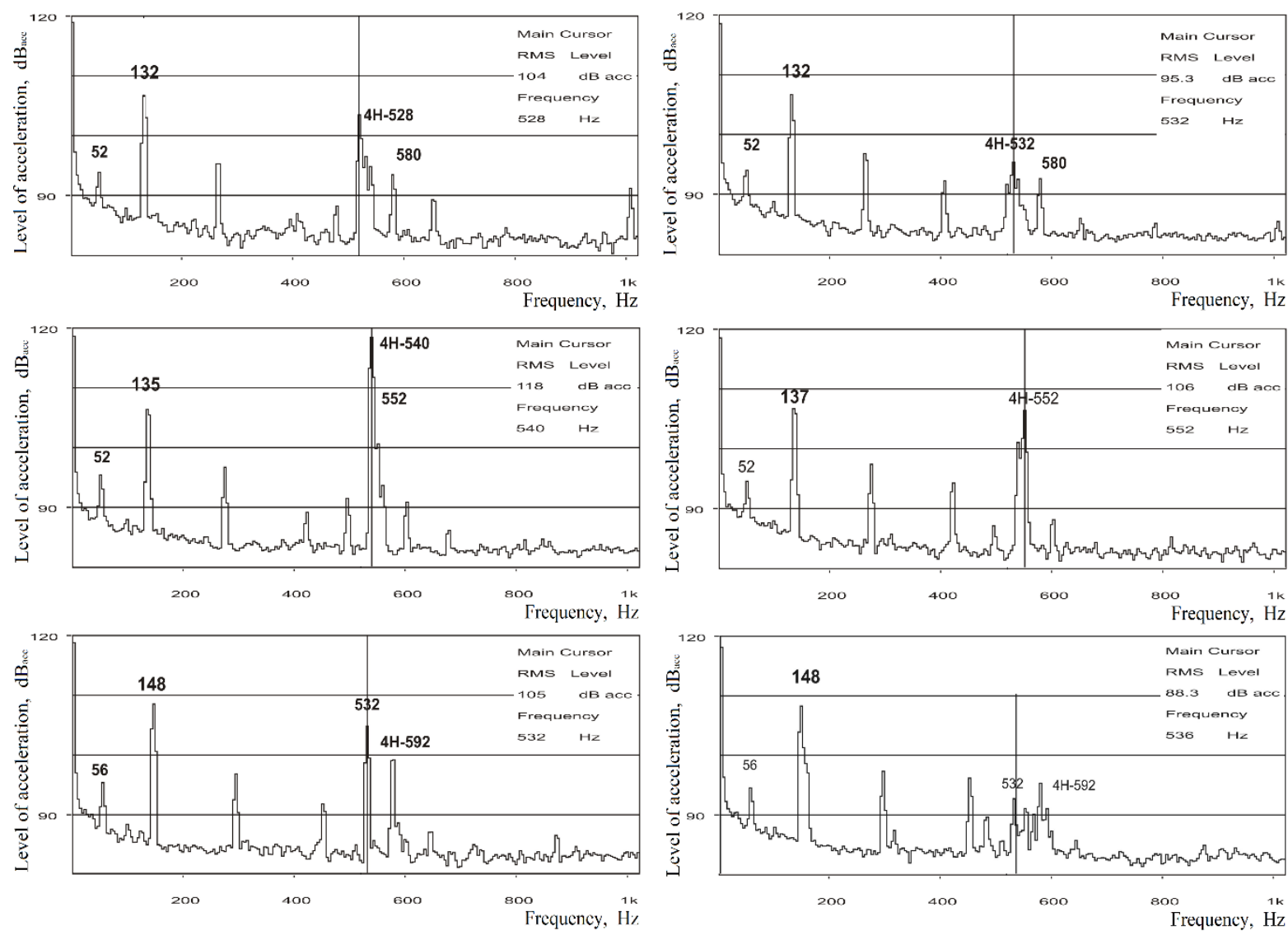

Fig. 5 Frequency spectra of electric motor No. 1 and No. 2 with new bearings in the area of increased dynamic load (left - unsatisfactory; right - satisfactory)

From the frequency spectra in Figure 5, the difference in the magnitude of the vibration amplitude in the region of the fourth harmonic $(4 \mathrm{H})$ rotational frequency can be clearly seen. In the assumed resonant region, Table 1 for the three selected frequencies and the two motors shows the vibration amplitudes at or near $4 \mathrm{H}$. One of the washing machine motors did not meet the specified requirements for dynamic loading in the range of its operating rotational frequencies. The amplitudes of the vibration acceleration of this electric motor are significantly higher than those of the electric motor that meets the specified criterion, i.e. the specified level of vibration acceleration, which corresponds to the limit noise emission level [11]. 
Table 1. Vibration amplitudes in or near the resonant region

\begin{tabular}{|c|c|c|}
\hline \multirow{2}{*}{ Frequency, $\mathrm{Hz}$} & \multicolumn{2}{|c|}{ Electric motor washing machine (CIM WH9) } \\
\cline { 2 - 3 } & Unsatisfactory, $\mathrm{dB}_{\mathrm{acc}}$ & Satisfactory, $\mathrm{dB}_{\mathrm{acc}}$ \\
\hline 132 & 103,5 & 95,3 \\
\hline 135 or 137 & 118 & 106 \\
\hline 148 & 105 & 88,3 \\
\hline
\end{tabular}

\section{DISCUSSION AND CONCLUSION}

The article presents two methodologies for determining the quality of manufactured bearings, which, however, have a common denominator, namely the vibration energy expressed by measuring the vibration acceleration and thus the undesirable increase in the noise of the machine system. The set criteria were verified and $100 \%$ agreement was reached in determining the quality of the bearings with respect to their dynamic exposure, namely maximum allowed vibration and noise. Unwanted bearing noise emissions can be monitored over the maximum acceleration value determined from the time history, the frequency distribution of the vibration and its equivalent level in the selected frequency range and with the bearings installed in the rotary machine using the acceleration level that corresponds to the emission limit level. Improving the quality of bearings, and thus reducing the number of unsatisfactory bearings, can be done by diagnosing the causes and faults of the bearings. In addition to structural deficiencies, the cause of poor quality (unsatisfactory) bearings, is also an insufficient and unprofessional installation. This observation follows from the performed frequency analysis.

In order to determine the cause of excessive vibration of the rotating components of the washing machine during coasting, or change the rotational frequency from $15000 \mathrm{r} / \mathrm{min}$ (spinning in the washing machine) to $5100 \mathrm{r} / \mathrm{min}$ (washing), it was necessary to calculate all the frequencies of possible faults to the individual components [11]. These were mainly frequencies caused by unbalance, misalignment of bearings, inappropriate clearance, bearing fault, electrical damage to the rotor and stator, as well as the calculation of critical rotational frequencies of the rotor of the electric motor. It was therefore necessary to perform a complete vibro-diagnostics of the electric motor and gradually eliminate its possible errors. It should be borne in mind that the increased imbalance supported by the unsatisfactory quality of the bearings can affect the overall dynamic behavior of the rotating components of the washing machine, especially in transient states such as a start-up and a run-down. Based on the frequency analysis, it can be stated that the amplitudes of the vibration quantities around the frequency of $540 \mathrm{~Hz}$ significantly change their value, which is characteristic of resonant phenomena, or for critical rotational frequencies of rotating components and their multiples. The probable cause of the undesired dynamic load of the motor is precisely the sub-resonance state, which is caused by a certain clearance in the bearing of the motor rotor, i.e. also in the bearings. It follows from the above that the cause of the increased dynamic load during the coasting of the electric motor is most likely a combination of greater rotor imbalance and greater clearance in the bearings [11].

\section{Acknowledgements}

The research presented in this paper is an outcome of the project no. APVV-19-0538 "Progressive hybrid high-speed spinning actuator" funded by the Slovak Research and Development Agency. 


\section{REFERENCES}

[1] Balážikova, M., Sinay, J. "Implementation of Auditory and Non-Auditory Effects of Noise in the Risk Assessment Process in Mechanical Engineering", Procedia Engineering 48, pp. $621-628,2012$.

[2] Čulík, M., Jochim, S., Ondrejka, V. "Sound Insulation of Partition Wall and Ceiling in Panel Timber Frame Structure”. Akustika 31, pp. 145 - 152, 2019.

[3] Flimel, M. "Possibilities of Active Reduction of Noise in the Workplace", Akustika 28, pp. $27-31,2017$.

[4] Chlebo, O., Šooš, L., Žiaran, S., Musil, M. "Application of Vibro-acoustics in Subjective and Objective Assessment of Bearing Quality". In: Proceedings of the International Conference Acoustics 2019, High Tatras 2019, pp. 203 - 208, 2019.

[5] Žiaran, S., Musil, M., Chlebo, O., Šooš, L. "Design of Vibration and Noise Level Control Methodology for Double-row Bearings K982 AS of Car Water Pumps". Research report of Mechanical Engineering Faculty Slovak University of Technology, Bratislava 2015.

[6] Žiaran, S., Musil, M., Chlebo, O. "Determination of the Bearing Quality by Means of Vibro-acoustic Response". In: Proceedings of Internoise/ASME NCAD Noise Control and Acoustics Division Conference 2015, Article Number: V001t01a004-1, 2015.

[7] Šlesar, P., Jančo, R. "Strength and Dynamic Assessment of Cage and Bearing for Railway Carriage", Strojnícky časopis - Journal of Mechanical Engineering 70 (1), pp. 127 - 134, 2020. DOI: $10.2478 /$ scjme-2020-0012

[8] Žiaran, S., Chlebo, O., Šooš, L. „Methodology of Objective Evaluation of Quality Bearings by Vibro-acoustics and its Comparison with a Subjective Method“, Akustika 37 , pp. $58-66,2020$.

[9] Žiaran, S., Chlebo, O., Čekan, M., Tuma, J. "Transmission of Vibrations through Vibration Isolators, Theory and Application". The 15th IFTOMM World Congress, Krakow, Poland, Springer Nature Switzerland AG 2019, pp. 3995 - 4004, 2019.

[10] Žiaran, S., Šooš, L., Chlebo, O. "Primary Noise Control in the Work Environment by Increasing the Quality of Bearings and Effective Mounting of Machines", Archives of Acoustics 45 (2), pp. 253 - 262, 2020.

[11] Žiaran, S. "Analysis of the Causes of Dynamic Loading of the CIM WH9 Electric Motor During Braking with a Proposal of Measures to Eliminate the Causes", Research report for EMERSON Nové Mesto nad Váhom 2006, 2006.

[12] Šlesar, P., Jančo, R. "The Calculation of the Contact Force and the Contact Width of Shaft Seals", Strojnícky časopis - Journal of Mechanical Engineering 69 (1), pp. 123 - 130, 2019. DOI: $10.2478 /$ scjme-2019-0010 